\title{
Influence of the Chelating Solutions in the Resistance of Glass Fiber Posts to the Root Dentin
}

\author{
Eduardo Fernandes Marques ${ }^{1}$ Marília Fagury Videira Marceliano-Alves ${ }^{2}$ Rina Andrea Pelegrine ${ }^{1}$ \\ Sérgio Luiz Pinheiro ${ }^{3}$ Carlos Eduardo Da Silveira Bueno ${ }^{1}$
}

1Department of Endodontics, São Leopoldo Mandic Dental Research Center, Campinas, São Paulo, Brazil

2Postgraduation Program, Iguaçu University, Nova Iguaçu, Brazil

${ }^{3}$ Department of Dentistry, Pontifícia Universidade Católica de Campinas (PUC-Campinas), São Paulo, Brazil
Address for correspondence Marilia Fagury Videira Marceliano-Alves, Iguaçu University, Av. Abílio Augusto Távora, 2134, Nova Iguaçu RJ 26260-045, Brazil (e-mail: mmarceliano@hotmail.com).

Eur ] Dent:2020;14:584-589

\begin{abstract}
Keywords

- chelating agents

- dental posts

- root canal irrigants

Objective This study aimed to evaluate the influence of chelating agents (EDTA, citric acid and Tetraclean) on glass fiber posts adhesion to root dentin.

Materials and Methods Forty mandibular premolars single canals, with complete apical root, straight, circular cross sections were selected, accessed and had the cervical third prepared with Gates-Glidden drills, then included in resin, instrumented with ProTaper Universal and the root canal obturation was carried out. After, the samples were randomly divided into 4 groups $(n=10)$ to test the final irrigation solutions: G1:17\% EDTA; G2:10\% citric acid; G3: Tetraclean and G4: saline solution (control). After 30 days of storage $\left(36.5^{\circ} \mathrm{C}\right.$ and $100 \%$ humidity), the post preparation was performed leaving $4 \mathrm{~mm}$ of apical endodontic filling. Then, a fiber-glass post previously selected was coated with ED Primer adhesive system and resin sealer Panavia, installed and stored for 24 hours at $37^{\circ} \mathrm{C}$. The samples were subjected to a tensile test with a constant speed of $1 \mathrm{~mm} / \mathrm{min}$ with $2000 \mathrm{Kgf}$. The results were analyzed with the ANOVA test.

Results The statistical analyzes indicated no significant differences between the groups $(p>0.05)$.

Conclusion The type of chelating agent used in the final irrigation of the endodontic treatment did not influence the tensile strength of the fixation system used to sealer the glass fiber posts to the intracanal dentin.
\end{abstract}

\section{Introduction}

The restoration of endodontically treated teeth has been generated discussions over the years. ${ }^{1}$ This procedure becomes extremely complex when teeth involved feature a large loss of tooth structure and reduction of resistance. ${ }^{2}$ Before a endodontically treated tooth restoration a clinical and radiographic assessment is important for appropriate planning. ${ }^{3}$ since the restoring technique selection aims to regain function, form, aesthetics, and protection of remaining tooth, and it is driven by the amount of remaining clinical crown, periodontal tissue condition, root morphology, occlusal habits, as well as by the filling of the root canal. ${ }^{4}$
Moreover, it is known that the use of metallic posts in the coronary anchorage supports the teeth reconstruction but may require a great loss of dentinal structure and so weaken the root structure. ${ }^{4}$ In addition, the metallic post modulus of elasticity is greater than the dentin's, which causes high dissipation of forces and teases wedge effect that, over time, can lead to fracture without the possibility of reconstruction of the root. ${ }^{5}$

With the development of new materials, allied to the evolution of the adhesive systems, there was the release of several types of premanufactured nonmetallic posts, which present as advantages: lower wear of the dental structure; 
adhesion to dentin through resin sealers; and simplification of the technique. ${ }^{6}$ Among the premanufactured posts, the glass fiber posts stand out because they possess a modulus of elasticity like that of the dentin, which enables the best distribution of strength, acceptable aesthetics, and radiopacity like dentin. ${ }^{7}$

The materials adhesive union of the intracanal dentin is considered a challenge due to the anatomical difficulties, the smear layer, and the physicochemical limitations of these materials. ${ }^{8}$ In addition, the irrigant solutions used during the root canals preparation can chemically alter the structure of the dentinal tissues. ${ }^{8,9}$

Many irrigating solutions are used during chemical-mechanical preparation. Analyzing the pertinent literature, it is observed the adhesive performance by the interference in dentin hybridization. ${ }^{10}$ These solutions would lead to a change in the collagen fibers of the dentin wall structure, besides being able to affect the calcium/phosphate ratio and interfere with the penetration of the monomer in the demineralized dentin. ${ }^{5,6,8,11}$ Consequently, the sealering process between the adhesive systems and the dental structure becomes deficient, reducing the quality and durability of direct restorations and restorations based on glass fiber posts. ${ }^{8,11}$

The sodium hypochlorite is a commonly used irrigating solution due to its antimicrobial and tissue solvent properties, so an additional solution is required for the inorganic layer of the smear layer removal. ${ }^{1-4}$ For this purpose, a chelant solution is used such as ethylenediaminetetraacetic acid (EDTA); MTAD (association between citric acid, doxycycline $3 \%$ of $\mathrm{mg} / 5$, and Tween 80 ); Tetraclean (association between citric acid, doxycycline $50 \mathrm{~mL}$ of $\mathrm{mg} / 5$, and propylene glycol), or Smear Clear (association between 17\% EDTA, Cetavlon, and Cetramide). ${ }^{2-11}$ The removal of this layer by these solutions is something significant because if this does not occur, this inorganic phase can serve as a physical barrier, interfering in the adhesion and penetration of sealing materials in the dentinal tubules. ${ }^{8,10,12,13}$

Therefore, the present study evaluated the influence of chelating agents on the sealer strength of glass fiber posts to root dentin. The null hypothesis was that the chelating agents would not influence the sealer strength of these posts to the dental structure.

\section{Materials and Methods}

\section{Sample Preparation}

The research was approved by the local research ethics committee under the protocol. Furthermore, the samples were divided distributed in four groups $(n=10)$ after sample calculation, with minimal difference between the average of the treatments of 0.20 , standard detour of the 0.12 error, number of treatments 4 , test power of 0.80 , and $\alpha$ of 0.05 .

From a pool of 400 mandibular premolars, 40 mandibular premolars were selected with single canals, with complete apical root, straight, and circular cross-sections in cervical, medium, and apical thirds and similar diameters measured in millimeters from digital radiography Schick CDR wireless
(Schick Technologies; Inc, Long Island City, New York, United States) (used at $60 \mathrm{kVp}, 10 \mathrm{~mA}$ e (1/6 seconds), Next, the greatest and smallest buccal-lingual root canal diameters were measured at each root third (coronal, middle, and apical) using a digital caliper. If a root canal displayed oval cross-section in two out of the three thirds, it was classified as oval and included in the sample. The teeth were stored in thymol 0.1\% (Fórmula e Ação, São Paulo, Brazil) and conserved by up to 3 months. ${ }^{9}$

The teeth were sectioned at the amelo-sealeral junction with a 22-mm diamond disc (Fava; São Paulo, Brazil) in low rotation. With the use of a digital caliper, the selected premolars had $15.0 \mathrm{~mm}$ of root. Premolars larger or smaller than $15.0 \mathrm{~mm}$ were discarded. The root canals were explored with a K file 15 (Dentsply-Sirona; Tulsa, EUA) until it was visualized in the apical foramen, and the working length established in $1 \mathrm{~mm}$ before this foramen ( $14 \mathrm{~mm})$. The apices were covered with wax 7 (Polidental; São Paulo, Brazil), and the roots were included in acrylic resin (VIPI Flash; São Paulo, Brazil).

The root canals were prepared with the ProTaper Universal system (Dentsply-Sirona) powered by the XSmart Plus motor (Dentsply-Sirona) in $3 \mathrm{Ncm}$ and $300 \mathrm{rpm}$ until F3. After each instrument, the canal was irrigated with $2.5 \% \mathrm{NaOCl}$ solution (Fórmula e Ação; São Paulo, Brazil), with a 30-gauge needle (Ultradent Products, Inc.; South Jordan, United States) and $3 \mathrm{~mm}$ short of the working length, using $30 \mathrm{~mL}$ of solution per tooth. In the end, the canals were dried with absorbent paper cones ProTaper Universal F3 (Dentsply-Tulsa; Oklahoma, United States).

The final irrigation procedure was performed in each group according to the different solutions tested (the distribution of teeth in each group was performed randomly): G1:17\% EDTA, G2:10\% citric acid, G3: Tetraclean and G4: saline solution (group control). In all groups, the canal was irrigated with $1 \mathrm{~mL}$ of solution, followed by ultrasonic vibration with 25 IRRI S insert (VDW Endo Ultrasonic Files; Endodontic Synergy, Munich, Germany) in the $30 \mathrm{kHz}$ frequency per 20 seconds, connected in a piezoelectric appliance (CVDent 1000; CVD Vale, São Paulo, Brazil). This process was repeated three times (using a total of $3 \mathrm{~mL}$ of the chelating solution), and it was followed by irrigation with $5 \mathrm{~mL}$ of $\mathrm{NaOCl}$ (Fórmula e Ação).

The root canals were dried again and filled with F3 gutta-percha cones coated with AH Plus sealer (KonstanzGermany), using the down-packing phase of the continuous compaction technique. ${ }^{14}$

\section{Fiber Postsealeration for Traction Test}

After 30 days of storage $\left(36.5^{\circ} \mathrm{C}\right.$ and $100 \%$ humidity), the canals were prepared with a $\mathrm{N}^{\circ} 1$ drill compatible with the white post DCE $\mathrm{N}^{\circ} 1$ post (FMG Odontologic Products LTDA, Joinville, Brazil) at a depth of $10 \mathrm{~mm}$ leaving $4 \mathrm{~mm}$ of apical endodontic filling. The posts were adjusted and using a digital radiography system Schick CDR wireless (Schick Technologies, Inc; Long Island City, New York, United States) at $60 \mathrm{kVp}, 10 \mathrm{~mA}$ and 1/6 seconds was performed the posts adaptation. The canal was irrigated with $2.5 \% \mathrm{NaOCl}$ solution (Fórmula e Ação), with 30-gauge needle (Ultradent Products, 
Inc; South Jordan, United States), with $1 \mathrm{~mL}$ of solution per tooth.

The posts were cleaned with isopropyl alcohol for 1 minute, and silane (PROSIL; FGM Dental Products LTDA Joinville, Brazil) was applied in an active form during 60 seconds with microbrushes (Microbrush; Grafton, Massachusetts, United States). The ED Primer adhesive system (Kuraray; Tokyo, Japan) was used mixing one drop of each bottle (A and B) and after applied on the dentin surface per 20 seconds with a microbrush. Then, the Panavia sealer (Panavia; Kuraray, Tokyo, Japan) was used according to the manufacturer instructions and was introduced into the canal using a Centrix (Centrix; Shelton, Connecticut, United States) syringe coupled with a needle point. Immediately after the post space preparation, the posts were positioned and the photoactivation was performed for 60 seconds in the cervical region of the roots, using the Optilight LD MAX (127V/220V), power-600 m Wcm-2, (Gnatus; Ribeirão Preto - Brazil).

\section{Resistance to Traction Test}

To carry out the adhesive resistance test, a cylinder with acrylic resin containing a metallic handle on the upper part was made over the coronary portion of the post. For the manufacture of these cylinders, $1.5 \mathrm{~cm}$ long disposable needle caps were used, which was fixed to radiographic films. These films had a central perforation that allowed the coronary part of the sealered pin penetration. Acrylic plastic was poured into each plastic cylinder and a 0.8 stainless steel orthodontic wire loop was placed on its upper portion. After resin polymerization, the samples were stored $\left(36.5^{\circ} \mathrm{C}\right.$ and $100 \%$ humidity) for 24 hours.

The samples were placed in the Universal Tests Machine (Emic DL2000; São Carlos, Brazil) for application in the axial load of traction at a speed of $1 \mathrm{~mm} /$ minute. The acrylic resin cylinder was fixed at the base of the machine, and the metallic strap was fixed in a cell of 2,000 Kgf. The machine automatically interrupted the operation when the post moved and the kilogram-force.

\section{Statistical Analysis}

The data were identified and subjected to statistical analysis. According to the results, nonparametric and parametric tests were indicated for the analyses. The Shapiro-Wilk test was initially applied to test for data normality. The one-way analysis of variance test was used by a factor analysis of variance. All tests were performed using SPSS 13.0 software for
Windows (SPSS Inc., Chicago, Illinois, United States). The significance level was established at $5 \%(p<0.05)$.

\section{Evaluation of the Fracture Pattern Types}

After rupture, the samples were prepared for analysis in scanning electron microscopy (SEM) (Phenom-World BV; Eindhoven, The Netherlands, Europe), performing dehydration with alcohol in increasing concentration, followed by "sputtering" with gold powder. Then, the roots were analyzed to evaluate the fractured surface in magnification of $\times 35,80,100$, and 170 . The posts fractured portion were classified in adhesive, mixed, and sealer cohesive failure. The first occurs when intra-radicular post is displaced, and the sealer and resin remain attached to the dentin; the second occurs when a cohesive failure happens when the sealer and resin detach with the intra-radicular post; and the latter happens when the intra-radicular retainer is displaced, and the sealer and resin remain attached to the dentin. ${ }^{9,10}$ All post fragments surfaces were quantified and expressed in percentage (-Table 2).

\section{Results}

According to the methodology described, - Table 1 points out that there were no significant differences between the four sample groups ( $p=0.7428$ ).

- Table 1 shows mean \pm standard deviation presented in the traction test (Kgf) after final endodontic irrigation with different solutions.

- Table 2 shows the fracture pattern found in SEM $(\times 100)$ after sealeration of the posts and traction test ( $\boldsymbol{- \text { Fig. }} \mathbf{1}$ ). The adhesive failure in the sealer/post interface was the most prevalent in the four groups studied ( - Table 2 ).

Table 1 Mean \pm standard deviation presented in the traction test (Kgf) after final endodontic irrigation with different solutions

\begin{tabular}{|l|l|}
\hline Irrigant solution & Mean \pm SD \\
\hline EDTA & $3.77 \pm 1.75^{\mathrm{a}}$ \\
\hline Citric acid & $4.58 \pm 2.34^{\mathrm{a}}$ \\
\hline Tetraclean & $3.57 \pm 2.28^{\mathrm{a}}$ \\
\hline Saline (control group) & $3.99 \pm 2.01^{\mathrm{a}}$ \\
\hline
\end{tabular}

Abbreviations: ANOVA, analysis of variance; EDTA, ethylenediaminetetraacetic acid; SD, standard deviation.

aSimilar letters: no statistical differences (ANOVA, $p>0.05$ ).

Table 2 Fracture types (\%) of the intracanal posts after final endodontic irrigation with different solutions

\begin{tabular}{|l|l|l|l|l|}
\hline \multirow{2}{*}{ Failure types } & \multicolumn{4}{|c|}{ Irrigant solution } \\
\cline { 2 - 5 } & EDTA & Citric acid & Tetraclean & $\begin{array}{l}\text { Saline } \\
\text { (control group) }\end{array}$ \\
\hline Sealer cohesive & 35 & 30 & 30 & 20 \\
\hline Adhesive fracture & 35 & 35 & 50 & 50 \\
\hline Mixed failure & 30 & 35 & 20 & 30 \\
\hline Total & 100 & 100 & 100 & 100 \\
\hline
\end{tabular}

Abbreviation: EDTA, ethylenediaminetetraacetic acid. 

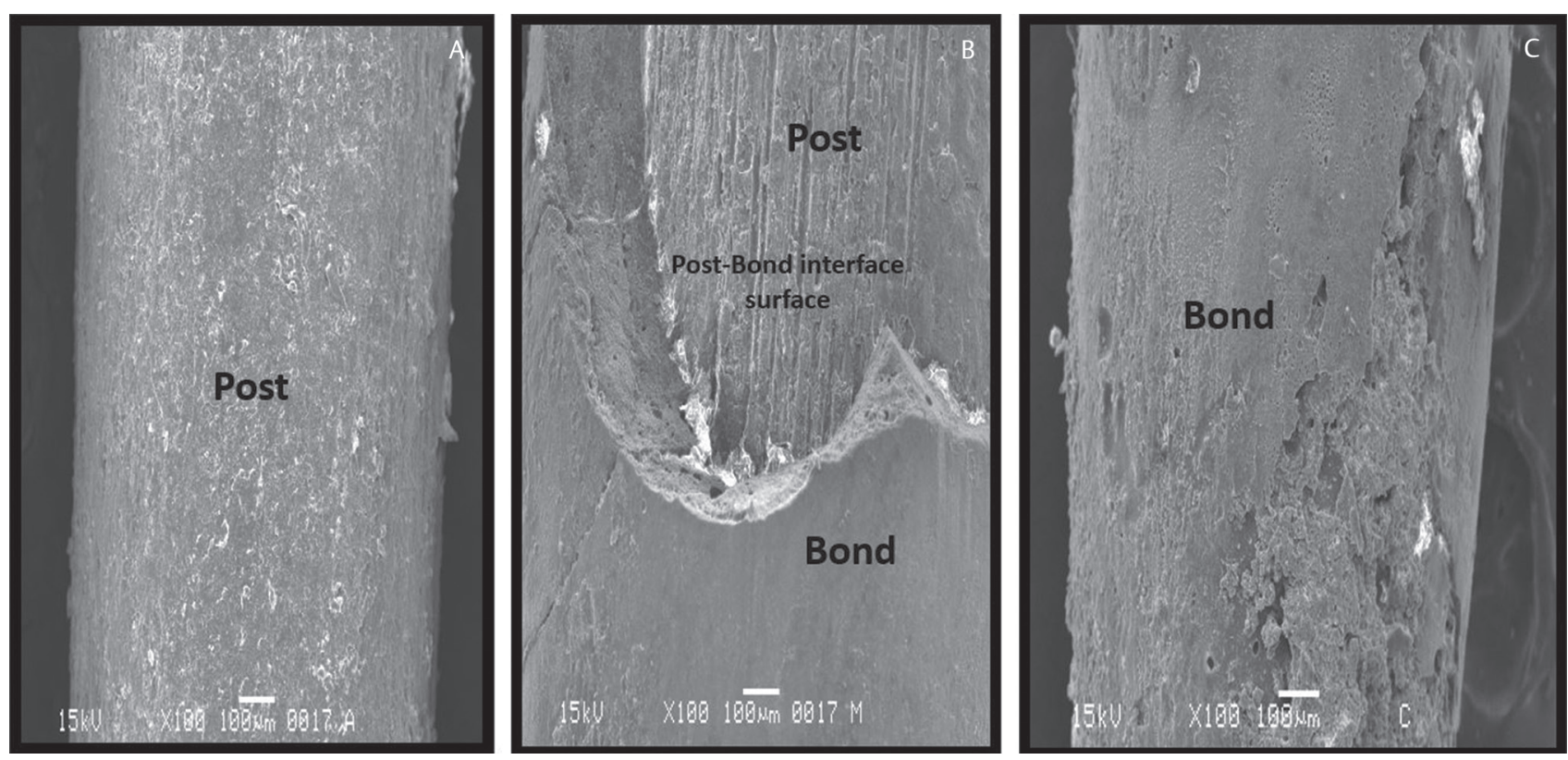

Fig. 1 Fracture pattern types found in scanning electron microscopy $(\times 100)$ after fiber postsealeration and traction test. (A) Adhesive failure at sealer/postinterface. (B) Mixed fracture. (C) Cohesive failure on sealer.

- Table 2 shows fracture pattern of the intracanal posts after final endodontic irrigation with different solutions.

Fracture pattern found in SEM $(\times 100)$ after fiber post sealeration and traction test: (A) adhesive failure at sealer/ post interface, (B) mixed fracture, and (C) cohesive failure in sealer (-Fig. 1).

\section{Discussion}

To obtain satisfactory adhesion of glass fiber posts to the root dentin is a primordial requirement, the smear layer removal, as well as the complete removal of all the remaining of endodontic sealer and gutta-percha on the walls of the canal. ${ }^{1}$ For this purpose, several chelating solutions are used, especially before the intracanal medication and the root canal filling. ${ }^{2}$ The most widely used chelating agent is 17\% EDTA, which acts on the inorganic portion of the dentin, exposing the dentin tubules. ${ }^{15}$ On the other hand, this solution does not provide antimicrobial potential and may lead to intracanal dentin erosion. ${ }^{16}$

The citric acid solution and Tetraclean could be used as alternative irrigants to smear layer removal and to supply some EDTA deficiencies. ${ }^{12}$ Tetraclean is active against bacteria responsible of endodontic primary infection such as Prevotella intermedia and Porphyiromonas gingivalis and against Enterococcus faecalis. ${ }^{17}$ A recent study confirmed the mechanism of the action of Tetraclean: it acts gradually over 72 hours to eliminate the bacterial load in all the samples tested. Due to the presence of doxycycline and to its substantivity, it binds to the dentine and then is released slowly. Unlike sodium hypochlorite, Tetraclean can achieve deep structure and penetrate dentin tubules because of its lower surface tension when compared with other tested irrigants. ${ }^{18}$
However, in this study, they presented similar results to EDTA, considering the adhesiveness of glass fiber posts to the root dentin. ${ }^{12,15,16,19,20}$ Thus, the null hypothesis was rejected because there was no difference the sealer strength of these posts to the dental structure $(p>0.05)$.

The evaluation of the influence of the EDTA solution for the intracanal dentin in this study was based on studies that affirmed that after its use, interference may occur in the microhardness of the dentin by a reaction with the calcium ions in the hydroxyapatite crystals. ${ }^{20}$ Citric acid solutions and Tetraclean were also inserted in the same time interval of EDTA, avoiding methodological biases.

Erosion, caused by irrigating solutions, has been widely evaluated in the literature with the use of SEM that allows a morphologic detailed evaluation of the prepared surface. ${ }^{21}$ According to the literature, ${ }^{20-22}$ depending on the depth, this erosion can be a contributing factor to the vertical root fracture but may contribute to the increasing rates of wallcleaning of the canal, removing debris and bacteria from the root canal. ${ }^{22,23}$

This study used a mechanical agitation by ultrasound due to its acoustic transmission and formation of bubbles due to the phenomenon of cavitation, which explodes and increases the temperature and pressure, resulting in waves of impact against the wall of the canal by removing debris. ${ }^{22-24}$ The debris removal process is aided by the continuous flow of the irrigating solution, promoting increased cleaning. ${ }^{25}$

A recent study showed that the dentin collagen could be affected by some endodontic solutions and that has the potential to influence the efficiency of adhesion of adhesive systems. ${ }^{24-26}$ This fact is relevant due to the increased use of resin sealers to the obturation of root canals, as well as of materials for sealering of fiberglass posts. Thus, studies affirmed that, after the use of some solutions, a residual layer can be left on the walls and over the dentin tubules, which 
can modify chemistry and structurally the dentin, preventing penetration and polymerization of the resinous monomers. ${ }^{27}$

The citric acid may be slightly powerful than the EDTA, ${ }^{10}$ at the same concentration, both agents show similar efficiency in the adhesive resistance of the fiberglass posts to the root dentin. ${ }^{20,24}$ In a recent study, the citric acid showed lower effect on dentin microhardness and did not change the resistance to fracture of the endodontically treated teeth compared with EDTA. ${ }^{28}$ However, other authors suggested that EDTA is used as a demineralizing agent for being a weak acid and perform a controlled demineralization of dentin, allowing the maintenance of the integrity of collagen fibers and the majority of intrafibrillar mineral. ${ }^{12,18}$

Some authors claim that the $\mathrm{NaOCl}$ may also lead to a shorter union resistance values when used adhesive systems, while those who used the $\mathrm{NaOCl}$ with EDTA association, verified best results, ${ }^{17,29}$ and also may increase the union resistance of self-conditioning adhesive systems. ${ }^{22,23}$

Studies report that the combination of $\mathrm{NaOCl}$ and EDTA results in a $\mathrm{pH}$ that favors the selective capability of the chelating agent to calcium ions, boosting their action. ${ }^{13,25,26}$ In addition, EDTA can selectively remove the hydroxyapatite and noncollagen proteins, avoiding drastic changes of the collagen fibers, ${ }^{25}$ which can conserve the intrafibrillar minerals, promoting stability and increasing the resistance to dehydration, favoring the adhesion. ${ }^{26}$

On the other hand, it is considered that the use of EDTA may increase the destructive effects of the $\mathrm{NaOCl}$ solution, 8,9 so the professionals should select irrigating solutions that cause fewer effects in the dentin properties, influencing, minimally, in adhesion process of root canal sealers and resinous materials used for sealeration. ${ }^{27}$

With different findings from previous studies, some authors showed lower values in union resistance when previous use of EDTA, which could be related to the methodology used or to the concentrations of the solution. ${ }^{11,28}$ Other studies highlighted that the removal of the smear layer was unfavorable to the adhesion of the resinous sealer to the root dentin when a self-conditioning system was used, which can be explained by the different composition of the dentinal surface resulting from the treatment with EDTA, becoming more demineralized, and hindering the formation of a stable adhesive interface between the resinous sealer and the radicular dentin, since the hybrid layer formed by these systems is thinner. ${ }^{13,17,18,28-30}$

The limitation of this study may be related to the distribution and density of the dentinal tubules in the different root regions. This happens since there are reports that the tubular density in the coronal region is greater than in the apical region and that the diameter of the tubules decreases in the apical direction. ${ }^{29}$

\section{Conclusion}

According to the applied methodology and the obtained results, it can be concluded that the chelating solution used in the final irrigation did not influence the tensile strength of the adhesive system associated with fiberglass posts to the intracanal dentin.

\section{Funding}

None.

\section{Conflict of Interest}

None declared.

\section{Acknowledgments}

This study was supported by grants from Fundação Carlos Chagas Filho de Amparo à Pesquisa do Estado do Rio de Janeiro, Brazilian Governmental Institution.

\section{References}

1 Onay EO, Yamanel K, Korkmaz-Ceyhan Y, Gulsahi K. Comparison of three adhesive systems in class II composite restorations in endodontically treated teeth: influence of Er: YAG laser conditioning and gingival margin levels on microleakage. J Clin Exp Dent 2018;10(8):e781-e788

2 Carbajal, Mejía JB, Wakabayashi K, Nakamura T, Yatani H. Fracture resistance of computer-aided design/computer-assisted manufactured glass-ceramic incisor crowns fabricated on reverse-tapered preparations. Int J Prosthodont 2018;31(5):478-480

3 Lima DER, Braga JMB, Sousa YS, Mourão ER, Nogueira SMA, Oliveira JA. Propriedades mecânicas dos postos intrarradiculares e sua influência na fratura de dentes tratados endodonticamente. Journal of Health Sciences 2017;19(5):1-2

4 Elsaka SE, Elnaghy AM. Bonding durability of titanium tetrafluoride treated glass fiber post with resin cement. Dent Mater J 2019;38(2):189-195

5 Grando CP. Avaliação in vitro da força de adesão comparando três adesivos dentinários na cimentação de postos intrarradiculares de fibra de vidro com e sem remanescente coronário submetidos a teste de tração. Campostas. Dissertação [Mestrado em Odontologia] - Centro de Pesquisas Odontológicas São Leopoldo Mandic. Available at: https://core.ac.uk/download/ pdf/30384234.pdf. Accessed 2009

6 Marques EF, Bueno CE, Veloso HH, Almeida G, Pinheiro SL. Influence of instrumentation techniques and irrigating solutions on bond strength of glass fiber posts to root dentin. Gen Dent 2014;62(2):50-53

7 Zehnder M. Root canal irrigants. J Endod 2006;32(5):389-398

8 Jitumori RT. Efeito da irrigação prévia na adesão de cimentos resinosos autoadesivos ao canal radicular na cimentação de postos de fibra de vidro. Ponta Grossa. Dissertação [Mestrado em Odontologia] - Universidade Estadual de Ponta Grossa. Available at: http://bdtd.ibict.br/vufind/Record/ UEPG_450a7e4da736657b2a67d6fd9918efeb 2018. Accessed 2009

9 Soares CJ, Soares PV, de Freitas Santos-Filho PC, Castro CG, Magalhaes D, Versluis A. The influence of cavity design and glass fiber posts on biomechanical behavior of endodontically treated premolars. J Endod 2008;34(8):1015-1019

10 Pelegrine RA, De Martin AS, Cunha RS, Pelegrine AA, da, Silveira, Bueno CE. Influence of chemical irrigants on the tensile bond strength of an adhesive system used to cement glass fiber posts to root dentin. Oral Surg Oral Med Oral Pathol Oral Radiol Endod 2010;110(5):e73-e76

11 Ali, Ahmad M, Zajac J, Prelot B. The effect of chelating anions on the retention of $\mathrm{Co}(\mathrm{II})$ by $\gamma$-alumina from aqueous solutions under the unadjusted $\mathrm{pH}$ condition of supported catalyst preparation. J Colloid Interface Sci 2019;535:182-194 
12 Violich DR, Chandler NP. The smear layer in endodontics - a review. Int Endod J 2010;43(1):2-15

13 De-Deus G, Paciornik S, Mauricio MHP. Evaluation of the effect of EDTA, EDTAC and citric acid on the microhardness of root dentine. Int Endod J 2006;39(5):401-407

14 Simezo AP, da, Silveira, Bueno CE, Cunha RS, et al. Comparative analysis of dentinal erosion after passive ultrasonic irrigation versus irrigation with reciprocating activation: an environmental scanning electron study. J Endod 2017;43(1):141-146

15 De-Deus G, Reis C, Fidel S, Fidel R, Paciornik S, Paciornik S. Dentine demineralization when subjected to EDTA with or without various wetting agents: a co-site digital optical microscopy study. Int Endod J 2008;41(4):279-287

16 Mohammadi Z, Giardino L, Palazzi F, Shalavi S. The effect of ascorbic acid on the substantivity of tetraclean in sodium hypochlorite-treated bovine dentin. J Dent (Tehran) 2012;9(3):230-236

17 Subramanian S, Appukuttan D, Tadepalli A, Gnana PP, Athmarao RT. Root conditioning with citric acid and ethylenediaminetetraacetic acid and their effect on fibrin clot adhesion to dentin-a scanning electron microscopic study. J Clin Diagn Res 2017;11(8):ZC82-ZC85

18 Pimentel, Corrêa AC, Cecchin D, de Almeida JF, Gomes BP, Zaia AA, Ferraz CC. Sodium thiosulfate for recovery of bond strength to dentin treated with sodium hypochlorite. J Endod 2016;42(2):284-288

19 Qian W, Shen Y, Haapasalo M. Quantitative analysis of the effect of irrigant solution sequences on dentin erosion. J Endod 2011;37(10):1437-1441

20 Mohammadi Z, Shalavi S, Yaripour S, et al. Smear layer removing ability of root canal irrigation solutions: a review. J Contemp Dent Pract 2019;20(3):395-402

21 Tartari T, Wichnieski C, Bachmann L, et al. Effect of the combination of several irrigants on dentine surface properties, adsorption of chlorhexidine and adhesion of microorganisms to dentine. Int Endod J 2018;51(12):1420-1433

22 Singh R, Pushpa S, Arunagiri D, Sawhny A, Misra A, Sujatha R. The effect of irrigating solutions on the apical sealing ability of MTA Fillapex and Adseal root canal sealers. J Dent Res Dent Clin Dent Prospect 2016;10(4):251-256

23 Arslan H, Yılmaz CB, Karatas E, Barutcigil C, Topcuoglu HS, Yeter KY. Efficacy of different treatments of root canal walls on the pull-out bond strength of the fiber posts. Lasers Med Sci 2015;30(2):863-868

24 Lottanti S, Gautschi H, Sener B, Zehnder M. Effects of ethylenediaminetetraacetic, etidronic and peracetic acid irrigation on human root dentine and the smear layer. Int Endod J 2009;42(4):335-343

$25 \mathrm{Gu}$ XH, Mao CY, Liang C, Wang HM, Kern M. Does endodontic post space irrigation affect smear layer removal and bonding effectiveness? Eur J Oral Sci 2009;117(5):597-603

26 Vangala A, Hegde V, Sathe S, Dixit M, Jain P. Effect of irrigating solutions used for postspace treatment on the push-out bond strength of glass fiber posts. J Conserv Dent 2016;19(1):82-86

27 Saghiri MA, Delvarani A, Mehrvarzfar P, et al. A study of the relation between erosion and microhardness of root canal dentin. Oral Surg Oral Med Oral Pathol Oral Radiol Endod 2009;108(6):e29-e34

28 Fan F, Ibrahim M, Dai P, et al. Effect of maleic acid on the bond strength of fibre posts to root dentine. Eur J Oral Sci 2017;125(5):396-402

29 Hayashi M, Takahashi Y, Hirai M, Iwami Y, Imazato S, Ebisu S. Effect of endodontic irrigation on bonding of resin cement to radicular dentin. Eur J Oral Sci 2005;113(1):70-76

30 Ferrari M, Mannocci F, Vichi A, Cagidiaco MC, Mjör IA. Bonding to root canal: structural characteristics of the substrate. Am J Dent 2000;13(5):255-260 